(2) OPEN ACCESS

\title{
Ethics of split liver transplantation: should a large liver always be split if medically safe?
}

\author{
Tae Wan Kim 이 , ${ }^{1}$ John Roberts, ${ }^{2}$ Alan Strudler, ${ }^{3}$ Sridhar Tayur ${ }^{4}$
}

${ }^{1}$ Ethics, Tepper School of Business, Carnegie Mellon University, Pittsburgh, Pennsylvania, USA

${ }^{2}$ Transplant Surgery, UC San Francisco Medical Center, San Francisco, California, USA ${ }^{3}$ Legal Studies and Ethics, The Wharton School, University of Pennsylvania, Philadelphia, Pennsylvania, USA

${ }^{4}$ Operations Management, Tepper School of Business, Carnegie Mellon University, Pittsburgh, Pennsylvania, USA

\section{Correspondence to} Dr Tae Wan Kim, Carnegie Mellon University, Pittsburgh, PA 15213, USA;

twkim@andrew.cmu.edu

Received 9 March 2021 Accepted 13 June 2021

\section{Check for updates}

(C) Author(s) (or their employer(s)) 2021. Re-use permitted under CC BY-NC. No commercial re-use. See rights and permissions. Published by BMJ.

To cite: Kim TW, Roberts J, Strudler A, et al. J Med Ethics Epub ahead of print: [please include Day Month Year]. doi:10.1136/

medethics-2021-107400

\begin{abstract}
Split liver transplantation (SLT) provides an opportunity to divide a donor liver, offering transplants to two small patients (one or both could be a child) rather than keeping it whole and providing a transplant to a single larger adult patient. In this article, we attempt to address the following question that is identified by the Organ Procurement and Transplant Network and United Network for Organ Sharing: 'Should a large liver always be split if medically safe?' This article aims to defend an answer-'not always' — and clarify under what circumstances SLT is ethically desirable. Our answer will show why a more dynamic approach is needed to the ethics of SLT. First, we discuss a case that does not need a dynamic approach. Then, we explain what is meant by a dynamic approach and why it is needed.
\end{abstract}

Split liver transplantation (SLT) provides an opportunity to divide a donor liver, offering transplants to two small patients (one or both could be a child) rather than keeping it whole and providing a transplant to a single larger adult patient. SLT is underused in the USA, and wider use may decrease death on the waiting list. ${ }^{1}$ In this article, we attempt to address the following question identified by the Organ Procurement and Transplant Network (OPTN) and United Network for Organ Sharing (UNOS): 'Should a large liver always be split if medically safe?"2 This article aims to defend an answer-'not always'-and clarify under what circumstances SLT is ethically desirable. Our answer will show why a more dynamic approach is needed to the ethics of SLT. First, we discuss a case that does not need a dynamic approach. Then, we explain what is meant by a dynamic approach and why it is necessary.

Some considerations limit the transplantation of portions of the liver. One is that there must be matching of the relative size of the donor and recipient because if the portion of the liver is too small for the recipient, it will fail. The most common split results in one portion of the liver that is about $75 \%$ of the original mass and one portion that is $25 \%$. The $25 \%$ is typically used in a child, whereas the larger portion is used in an adult. The $75 \%$ portion may not be adequate for a large adult for whom $100 \%$ of the liver would be adequate. Other limitations are the logistical issues such as preparing two recipients for the operating room, the time and expertise required to split the liver, and the transport of the portions of the liver.

\section{ULTIMATUM}

We begin with a simple case, which we call 'Ultimatum.' Suppose that there are three patients: one large adult, one small adult and one child (or one large adult, one child and one infant). Also, suppose that the three patients are equally seriously ill and will die unless they receive transplants immediately. Now, a large donor liver has become available. As a result, the surgeon has two options ${ }^{\text {ii }}$ :

- 'Split': Divide the liver and give part to the child and the other to the small adult.

- 'Do not split': Use one whole donor liver, as it is, for the large adult patient.

In this scenario, regardless of whether more donated livers will be forthcoming or not, the surgeon faces the ultimatum. It is not necessary to think about the future supply of livers because a decision has to be made now.

What should the surgeon do? Regarding the ethics of SLT, Vulchev et al proposed in 2003 two principles-that is, utility-maximisation and fairness-as follows:

\section{Maximizing the number of patients receiving organ transplants, so long as individual patients do not suffer disproportionate costs for societal benefit, and maximizing the individual patient's survival, so long as society does not suffer disproportionate costs for individual benefit (emphasis added). ${ }^{3}$}

We agree with Vulchev et al's idea that both utility and comparative justice/fairness must be considered at the same time.

In the past, SLT generally led to less favourable results for individual recipients even though the splitting of a liver maximised the number of patients receiving an organ transplant. Thus, it was not entirely clear which of the above two options to recommend, as the post-transplant benefits were unequal. Currently, longer-term outcomes (eg, survival rate) of SLT are approximately similar to those for the whole liver transplant, ${ }^{4}$ iii and although SLT may carry higher perioperative morbidity, some reports suggest similar morbidities. ${ }^{5}$ Given the improvement in outcomes, two paediatricians (Kim and Vakili) have recently argued that it is time

${ }^{\mathrm{i}}$ The three patients have similar risks of death measured by their Model for End-Stage Liver Disease (MELD) and Pediatric End-Stage Liver Disease (PELD) scores. Here, we are not arguing that MELD or PELD should be the only criterion. In this paper, we do not make an argument about which criteria should be used to determine moral urgency. Whatever reasonable criteria are used, just suppose that the need of the three patients for a liver transplant is equal and acute.

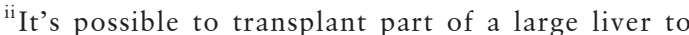
a large patient (who would probably want it if that were the only option). But for simplicity's sake, we will focus on cases where the success rates are similar.

${ }^{\text {iii }}$ See, for instance, Hashimoto ${ }^{4}$ 
to split livers to save two people (including children). ${ }^{6}$ Simply put, they make a utilitarian argument that saving two patients produces greater aggregate good consequences than saving one patient—and that it is therefore the right thing to do.

We agree with Kim and Vakili that 'Split' is the right thing to do. Here, we strengthen the claim by arguing that 'Split' is, in fact, fair as well as utility-maximising. Our argument further develops Kim and Vakili's idea and is also consistent with OPTN's and UNOS's Joint Ethics Committee's white paper, which proposes: 'The transplant community has an ethical obligation to maximise the outcomes from donated organs, while also promoting equity." In fact, the ethics committee 'feel[s] that it is fair and efficient ... to split the liver for [a] child and a larger (adult or paediatric) candidate in whom the extended right lobe graft is size-appropriate (emphasis added). ${ }^{\text {,iv }}$ The ethics committee did not clearly offer a normative argument as to why 'Split' is fair. It is straightforward that, in terms of utility-maximisation, 'Split' is the right choice. But it is indeed less clear why the same choice follows the fairness principle. Below, we philosophically clarify why 'Split' is fair, providing two kinds of fairness-based arguments.

\section{The balancing argument}

If our question regarded which two qualitatively equal patients to save (one patient vs one patient), tossing a coin would be a way to treat the two equally. ${ }^{8 \mathrm{v}}$ But if the surgeon tossed a coin in our context (one patient vs two patients)-acting no differently than she would in the contest between one patient and one patient-then she would not recognise the equal importance of the additional patient in 'Split.' In other words, the additional patient would play no role in the surgeon's decision making if she tossed a coin. In such a scenario, the surgeon would be treating the additional person as if she did not exist, which is a violation of the equal value of the additional person. To use moral philosopher Kamm's words, the additional patient is not 'balanced out.' 910 vi In fact, all three patients are disrespected, because by choosing 'Do not split,' the surgeon treats all of them with a decision rule that does not ensure that each patient makes a difference.

If equality is all that matters, why not give each patient onethird weight in the decision? This approach may meet the requirement of equal consideration for each. But, even if the approach meets the demand of equal consideration, it does not meet the other value-utility-maximisation-used in OPTN and UNOS. The proportionate approach can end up saving only one person. Additionally, a more careful investigation of equal consideration, which we will now move to, will further clarify why saving two is fairer-as well as more utility enhancingthan saving one.

\section{The non-consequentialist importance of consequence}

The surgeon has a duty to treat the three patients with a decision rule that respects the equal importance of each. However, the surgeon cannot perfectly comply with this duty, because the availability of the donor organs does not perfectly match the need for organs. But note that she can, to her best extent, partially comply with a duty. ${ }^{11}$ Thus, the kind of right that the

\footnotetext{
${ }^{\text {iv }}$ Ibid., 7.

${ }^{\mathrm{v}}$ This is also called the 'Kamm-Scanlon Argument,' developed by Frances Kamm and reformulated by Thomas Scanlon into a more contractualist form. See Kamm ${ }^{9}$

${ }^{\mathrm{vi}} \mathrm{A}$ more fundamental principle underlying the balancing argument is Thomas Nagel's 'pairwise comparison'. See Nagel ${ }^{10}$
}

surgeon owes to the patients is not full-blown but qualified: a duty to save the patients to the extent that she can, consistent with the equal importance of each person.

If a person is obligated to save people equally but does not have enough resources to save each life that is at stake, then she should make a choice that best approximates an equal distribution. ${ }^{12}$ If the surgeon has three donor organs, she can perfectly comply with the duty to provide equal treatment. What makes $3 / 3$ the best in terms of equal consideration is that the choice is the broadest allocation. The next broadest allocation is $2 / 3$. So, from the perspective of the equal importance of each individual, 'Split' is the best. In the circumstance she faces, 'the best is less than perfect. ${ }^{\text {,vii }}$ Because this argument appeals to equality rather than aggregate utility, it is not a utilitarian argument; such a utilitarian rationale would be that 2/3 maximises the total utility, no matter what procedures are used. Our fairness-based rationale-which is that $2 / 3$ gives the best equal consideration to people-is distinct from a utilitarian one. ${ }^{13}$ The point is that, regardless of outcomes, the surgeon should make a choice that is in accordance with a decision rule that best approximates the value of equal consideration.

Why should $3 / 3$ be the anchor to approximate equality? For instance, $0 / 3$ is also equal. If no one gets the liver, that is, as equal as $3 / 3$ (and closer to equal than 2/3). From a formal view of equality, there is no difference between $3 / 3$ and $0 / 3$. The problem with the $0 / 3$ strategy is that it is not close to an equal distribution of value. Suppose that a rescuer refuses to save any person among ten who are drowning, even though he can do so without any significant risk; he justifies his inaction on the grounds that, by giving each person nothing, he treats each equally. He appears to not consider the value of human life in any of the drowning people, expressing what the law often calls 'depraved indifference. ${ }^{14}$ viii The $2 / 3$ scenario better approximates an equal distribution than a zero distribution, because a zero distribution is no distribution at all.

\section{A DYNAMIC APPROACH \\ Mezzanine}

Moving onto dynamic cases, let us first consider a not fully realistic case, though it is representative enough to be instructive for the next step of our reasoning. We add two additional conditions to ultimatum - with the understanding that a vast number of large patients are almost always present on the waiting list and donor livers are almost always coming in, though when, how many, and what type is unpredictable (though there are some predictable patterns).

Now, consider the mezzanine case. Suppose there is one large adult, whose Model for End-Stage Liver Disease (MELD) score is very high and who will soon die unless receiving a transplant immediately, while there are two small patients (one child and one small adult), who can wait for 6 months without too much risk. Based on the past pattern, it is likely that a large liver will become available within 6 months. The surgeon has two options:

- 'Split': Divide the liver and give part to the child and the other part to the small adult.

- 'Do not split': Use one whole donor liver, as it is, for the large adult patient.

\footnotetext{
${ }^{\text {vii Ibid. }}$

viii One might say that equality is a secondary duty, whereas saving people is a primary duty, so equality is used to break ties. We partly agree. But equal consideration is a thick concept that cannot be fully understood unless the two duties are combined in our context.
} 
In terms of utility-maximisation, it is good to save the large adult first, because the two small patients will likely be saved eventually.

How about fairness? Is there an interpretation of fairness that is appropriate for the case? We find John Rawls's well-known idea of the difference principle or maximin to be suitable. ${ }^{15}$ The idea explains what justice requires in situations where an equal distribution is not morally optimal, such as those faced regarding liver transplants. In our context, the size of patients results from, to use Rawls's term, 'the natural lottery.' That is, it is just a matter of luck, and hence morally irrelevant in terms of fairness, whether a patient is large or small.

To eliminate the impact of the morally irrelevant factors, following Rawls's idea of a 'veil of ignorance,' let us imagine a hypothetical social contract space where the patients, who do not know whether their body sizes are large or small, meet together and decide which of the two options to choose. In the absence of knowledge about their own body size, rationality demands that patients choose 'Do not split.' The decision-makers know that if the large patient does not receive a transplant now, he will die, whereas the small patients are likely to receive a liver relatively soon. Hence, all the patients behind the veil of ignorance have a rational reason to accept 'Save the big patient first.' So, the choice that meets fairness and utility-maximisation is 'Not split' in this case.

An apparent problem of the Mezzanine case is that it is not yet realistic enough. There is likely more than one large patient on the waiting list whose MELD score is very high. So, the next scenario is not one in which there are only small patients (with no competition with a large adult). A more realistic view is that the two small patients should compete with another seriously ill large patient. If the cases of all three patients are equally acute at that moment, the case becomes Ultimatum, and it will be ethical to save the two small patients. But what if they are still not as seriously ill as the new large patient? Their waiting time gets longer, and they get sicker. They can wait for approximately 3 months, but no longer. If this happens again and again, there will be disparate impact against small patients.

A twin case is that there is one big patient whose MELD score is not that high and two small patients (one child and one small adult) whose MELD or Pa ediatric End-Stage Liver Disease (PELD) scores are very high, meaning they will die unless they receive transplants immediately. In terms of utility-maximisation, saving the two small patients is correct. In terms of fairness, using maximin with the veil of ignorance, anyone would choose to save the two small patients first, because the large adult would likely be saved in due course. But the same thing that happened in the above dynamic can happen here as well. What if the large patient competes with two new seriously ill small patients in the next session? If all three patients are seriously ill, it becomes ultimatum once again and it's the correct course to save two small patients. In that case, there will be disparate impact on big patients.

The twin cases can be combined in reality, in which case disparate impacts oscillate between the two groups: large and small patients.

\section{A dynamic approach}

How can disparate impact in dynamic cases be addressed? The possibility shows that a MELD or PELD score may not be the only aspect of fairness; waiting time may be another one-and there may be yet others. In this paper, we don't need to exhaustively discuss the full list of what constitutes fairness in SLT. Our view is that the medical community should reach reasonable consensus about the list. ${ }^{16} 17$ The focus of this paper is, rather, to offer a generic framework that can address the disparate impact in dynamic cases.

We now want to extend the maximin principle to a dynamic case. To do so, we need to choose which group is the worst-off. Suppose, for the sake of argument, that small patients are the worst-off parties (measured in any number of ways, such as probability of transplant, sickness at transplant, time spent waiting for a transplant) at time $t_{1}$. The primary goal of our paper is to show that, although ultimatum is a possible scenario, much of the ethics of SLT is a dynamic problem whose answer requires a dynamic solution (which we will explain shortly).

Continuing to save the small patients in an ongoing manner will at some point lead to a disparate impact on large patients, who at time $t_{2}$ would become the worst-off group. Then maximin requires the physician to start saving large patients, which would occur, if done in an on-going manner, at $t_{3}$, with a disparate impact on small patients-bringing the system back to how it was at $t_{1}$. We would then return to saving the small patients, and a new cycle ensues. This seems to be a vicious cycle at first glance, but the problem we are dealing with is dynamic, so the solution must be dynamic and oscillate qualitatively between the different demographics. In fact, the dynamic maximin can be quantified, and so operationalised, by a suitably constructed dynamic optimisation. ${ }^{18}$

Then, we need an answer on how to conclude: 'Okay, now small parties are no longer the worst-off parties.' There must be an operational standard that switches the priority. Fully answering this question-what must be part of the standardis beyond the capacity of this paper, but let us briefly illustrate what can be the operational standard.

In terms of which group is the worst-off, there may be various factors to measure. Take three of them:

- Likelihood of death (or removal from recipient list due to being too sick) in the next 90 days.

- Wait time until transplant (typically meaning a patient will be sicker the longer they wait and enjoy fewer additional years of life).

- Probability of obtaining a transplant.

All are related to the number of patients on the list. Thus, these are all, in an operational sense, measuring the 'same' thing. Given that we cannot give transplants to everyone and that even those who do get them may have to wait quite a bit, one way of tracking is to have what operations researchers call 'state'-the number of patients waiting, average wait time, fraction of patients transplanted, MELD or PELD score at transplant, number of additional years of life gained, etc-and define fairness between different subdivisions of patients who are competing for the same liver (in our paper, small and large patients). The goal is to keep the states of the groups as close as possible across time. There are well-known measures of 'closeness' that can be applied. ${ }^{19}$ This will lead to a dynamic allocation policy that oscillates between splitting a large liver (if the health states of the small patient group are worse than the large patient group) or not (the opposite situation).

The dynamic Rawlsian approach can be made more sophisticated, if needed. Above, we used only two options: 'Split' and 'Do not split.' If adding more options keeps the states of the subgroups as close as possible across time, doing so better serves the ideal of dynamic maximin:

- 'Split' type 1: Divide the liver and give 25\% to the child and the other part to the small adult.

- 'Split' type 2: Divide the liver and give $60 \%$ to the large adult and the other part to the small adult. 
- 'Do not split': Use one whole donor liver, as is, for the large adult patient.

If adding more than two subgroups (eg, small, medium and large) better reflects patients in real life, doing so is a consideration, too.

\section{Policy implications}

If we want to encourage SLT when it is an ethical choice, especially in ultimatum-like cases, a factor to consider is the incentive to split a liver. For example, in countries like Germany, if you split an organ for a recipient, the second part of the organ may be allocated to a patient in a different centre. In this setting, the motivation to split for the centre originally offered the whole liver will not be high, because its patients will not benefit from the splitting. To address this, the US has a variance that allows the centre that is offered a whole liver to split the liver and offer each portion to one of that centre's patients. ${ }^{\text {ix }}$

As we discussed, the reality is more akin to dynamic cases. To help evaluate possible policy changes, a flexible decision support model is being developed to allow for 'what-if' analyses considering various fairness and efficiency metrics. The numerical study is being conducted using data from UNOS. ${ }^{\mathrm{x}}$ Additionally, because the skills required for SLT are gained by doing, a second model is being developed by researchers to gain insights into how surgeons can best gain these skills over time, balancing outcomes for today with building additional capacity for the future. ${ }^{20}$

\section{CONCLUSION}

We hope our analysis of the ethical implications of SLT - using philosophical theory, even with its limitations-is helpful to the transplant community. Should a large liver always be split if medically safe? Answer: 'No.' In dynamic cases, the right decision will oscillate between 'split' and 'do not split.' Ethicists also should think about dynamic cases as well as the usual scenarios such as ultimatum.

Acknowledgements We thank Alan Scheller-Wolf, Yanhan Tang, Rebekah Apple (Carnegie Mellon University), Ali Al-Khafagji, David Wallace (University of Pittsburgh Medical Center), Tinglong Dai (Johns Hopkins University), and Emily Perito (University of California, San Francisco Medical Center) for comments that greatly improved the manuscript.

Contributors All authors substantially contributed.

Funding The authors have not declared a specific grant for this research from any funding agency in the public, commercial or not-for-profit sectors.

Competing interests None declared.

\footnotetext{
${ }^{\text {ix }}$ Organ Procurement and Transplantation Network, 'Split liver variance', 12/2019.

${ }^{\mathrm{x}}$ See Reference ${ }^{18}$.
}

Patient consent for publication Not required.

Provenance and peer review Not commissioned; externally peer reviewed.

Data availability statement There are no data in this work.

Open access This is an open access article distributed in accordance with the Creative Commons Attribution Non Commercial (CC BY-NC 4.0) license, which permits others to distribute, remix, adapt, build upon this work non-commercially, and license their derivative works on different terms, provided the original work is properly cited, appropriate credit is given, any changes made indicated, and the use is non-commercial. See: http://creativecommons.org/licenses/by-nc/4.0/.

\section{ORCID iD}

Tae Wan Kim http://orcid.org/0000-0001-6572-9669

\section{REFERENCES}

1 Perito ER, Roll G, Dodge JL, et al. Split liver transplantation and pediatric waitlist mortality in the United States: potential for improvement. Transplantation 2019;103(3):552-7.

2 OPTN/UNOS Ethics Committee. Split versus whole liver transplantation. OPTN/UNOS public Comment proposal, 2016.

3 Vulchev A, Roberts JP, Stock PG. Ethical issues in split versus whole liver transplantation. Am J Transplant 2004:4(11):1737-40.

4 Hashimoto K, Eghtesad B. Split liver transplantation. In: Cataldo D, ed. Contemporary liver transplantation: the successful liver transplant program. Cham, Switzerland: Springer, 2017: 81-97.

5 Moussaoui D, Toso C, Nowacka A, et al. Early complications after liver transplantation in children and adults: are split grafts equal to each other and equal to whole livers? Pediatr Transplant 2017;21(4). doi:10.1111/petr.12908. [Epub ahead of print: 0503 2017].

$6 \mathrm{Kim}$ HB, Vakili K. To split or not to split? that is no longer the question. J Pediatr 2018;196:12-13.

7 OPTN/UNOS Ethics Committee. Split versus whole liver transplantation. OPTN/UNOS public Comment proposal, 2016. Available: https://optn.transplant.hrsa.gov/media/ 1919/ethics_splitvwhole_livertx_20160815.pdf

8 Scanlon T. What we owe to each other. Cambridge, MA: Belknap Press, 1998: 228-41.

9 Kamm FM. Morality, mortality: rights, duties, and status. New York: Oxford University Press, 2001: 99-121.

10 Nagel T. Equality. In: Mortal questions. New York: Cambridge University Press, 1979.

11 Raz J. Numbers, with and without Contractualism. Ratio 2003;16(4):346-67.

12 HSIEH NIEN-HÊ, Strudler A, Wasserman D. The numbers problem. Philos Public Aff 2006;34(4):352-72.

13 HSIEH NIEN-HÊ, Strudler A, Wasserman D. Pairwise comparison and numbers skepticism. Utilitas 2007;19(4):487-504.

14 Wasserman D, Strudler A. Can a Nonconsequentialist count lives? Philos Public Aff 2003:31(1):71-94.

15 Rawls J. A theory of justice. Cambridge, MA: Harvard University Press, 1971.

16 Daniels N, Sabin J. Setting limits fairly: can we learn to share medical resources? New York: Oxford University Press, 2002.

17 Persad G, Wertheimer A, Emanuel EJ. Principles for allocation of scarce medical interventions. Lancet 2009:373(9661):423-31.

18 Tang Y, Scheller-Wolf A, Tayur S. A decision-support model for split liver transplantation [working paper]. Tepper School of Business, Carnegie Mellon University, 2020. https://papers.ssrn.com/sol3/papers.cfm?abstract id=3877523

19 Ata B, Friedewald JJ, Renda AC. Organ transplantation. In: Dai T, Tayur S, eds. Handbook of Healthcare Analytics [ch. 9]. Hoboken, NJ: Wiley, 2018.

20 Tang Y, Li A, Scheller-Wolf A. Generalized bandits with learning and queueing in split liver transplantation [working paper]. Tepper School of Business, Carnegie Mellon University, 2021. https://papers.ssrn.com/sol3/Papers.cfm?abstract_id=3855206 